Journal for ImmunoTherapy of Cancer

\title{
T lymphocyte-targeted immune checkpoint modulation in glioma
}

\author{
William James Kelly, Amber Jin Giles, Mark Gilbert
}

To cite: Kelly WJ, Giles AJ, Gilbert M. T lymphocytetargeted immune checkpoint modulation in glioma. Journal for ImmunoTherapy of Cancer 2020;8:e00379. doi:10.1136/ jitc-2019-000379

Accepted 05 January 2020

Check for updates

(C) Author(s) (or their employer(s)) 2020. Re-use permitted under CC BY-NC. No commercial re-use. See rights and permissions. Published by BMJ.

Neuro-Oncology Branch, National Cancer Institute, Bethesda, Maryland, USA

Correspondence to Dr William James Kelly; 08wkelly@gmail.com

\begin{abstract}
Immunomodulatory therapies targeting inhibitory checkpoint molecules have revolutionized the treatment of solid tumor malignancies. Concerns about whether systemic administration of an immune checkpoint inhibitor could impact primary brain tumors were answered with the observation of definitive responses in pediatric patients harboring hypermutated gliomas. Although initial clinical results in patients with glioblastoma (GBM) were disappointing, recently published results have demonstrated a potential survival benefit in patients with recurrent GBM treated with neoadjuvant programmed cell death protein 1 blockade. While these findings necessitate verification in subsequent studies, they support the possibility of achieving clinical meaningful immune responses in malignant primary brain tumors including GBM, a disease in dire need of additional therapeutic options. There are several challenges involved in treating glioma with immune checkpoint modulators including the immunosuppressive nature of GBM itself with high inhibitory checkpoint expression, the immunoselective blood brain barrier impairing the ability for peripheral lymphocytes to traffic to the tumor microenvironment and the high prevalence of corticosteroid use which suppress lymphocyte activation. However, by simultaneously targeting multiple costimulatory and inhibitory pathways, it may be possible to achieve an effective antitumoral immune response. To this end, there are now several novel agents targeting more recently uncovered "second generation" checkpoint molecules. Given the multiplicity of drugs being considered for combination regimens, an increased understanding of the mechanisms of action and resistance combined with more robust preclinical and early clinical testing will be needed to be able to adequately test these agents. This review summarizes our current understanding of T lymphocyte-modulating checkpoint molecules as it pertains to glioma with the hope for a renewed focus on the most promising therapeutic strategies.
\end{abstract}

\section{THE PROMISE OF IMMUNOMODULATORY CHECKPOINT THERAPIES}

Immunomodulatory therapies targeting inhibitory checkpoint molecules have revolutionized the treatment of solid tumor malignancies. ${ }^{1}$ Concerns about whether systemic administration of an immune checkpoint inhibitor could impact primary brain tumors were answered with the observation of definitive responses in pediatric patients harboring hypermutated gliomas. ${ }^{2}$ Although initial clinical results in patients with glioblastoma (GBM) were disappointing, recently published results have demonstrated a potential survival benefit in patients with recurrent GBM treated with neoadjuvant programmed cell death protein 1 (PD-1) blockade. ${ }^{3}$ While these findings necessitate verification in subsequent studies, they support the possibility of achieving clinical meaningful immune responses in malignant primary brain tumors including GBM, a disease in dire need of additional therapeutic options.

There are several challenges involved in treating glioma with immune checkpoint modulators. First is the immunosuppressive nature of GBM itself, with its high expression of inhibitory checkpoint molecules and cytokines such as tumor growth factor beta (TGF- $\beta$ ), vascular endothelial factor (VEGF), and interleukin 10 (IL-10). ${ }^{4-9}$ Second, glioma tumors arise within the immunoselective blood brain barrier, thus impairing the ability for peripheral lymphocytes to traffic to the tumor microenvironment. However, recent studies in melanoma and non-small cell lung cancer have demonstrated that immune checkpoint inhibitors can indeed achieve intracranial response. ${ }^{10-12}$ It is hypothesized that immune cells transverse the meninges through the fenestrated endothelial and tight-junction epithelial layers of the choroid plexis. ${ }^{13}$ Alternatively, immune cells may directly migrate through meningeal blood vessels. In rat models, effector $\mathrm{T}$ lymphocytes have demonstrated the ability to transgress vascular walls into the cerebrospinal fluid (CSF).${ }^{14}$ Finally, immune modulation therapy in patients with glioma is complicated by the high prevalence of corticosteroid use which inhibits lymphocyte activation. ${ }^{516}$

By simultaneously targeting multiple costimulatory and inhibitory pathways, it may be possible to achieve an effective antitumoral immune response. To this end, there are now several novel agents targeting more recently uncovered "second generation" checkpoint molecules. This review summarizes our 
current understanding of $\mathrm{T}$ lymphocyte-modulating checkpoint molecules as it pertains to glioma with the hope for a renewed focus on the most promising therapeutic strategies. Additionally, the current clinical trials investigating immune checkpoint inhibitors in glioma or GBM are referenced in tables 1 and 2.

\section{TARGETING ACTIVATORS OF EFFECTOR T CELLS}

Activating, also known as costimulatory, molecules promote effector $\mathrm{T}$ cell differentiation, proliferation, and activation. Effector T cells expressing the coreceptor CD8 recognize tumor peptides on antigen presenting cells (APC) through the interaction of the T-cell receptor (TCR) and major histocompatibility complex (MHC). Treatment with an antibody agonist targeting a costimulatory response can upregulate this signaling leading to enhanced cytotoxic $\mathrm{T}$ cell activity and ultimately tumor quiescence or regression. The costimulatory molecules with the most potential for further development are reviewed below.

\section{4-1BB}

4-1BB, also known as CD137, is a costimulatory receptor expressed on the surface of activated $\mathrm{T}$ cells as well as natural killer (NK) cells. 4-1BB plays a role in cytokine section, antiapoptotic signaling, NK cytotoxicity and promotion of $\mathrm{T}$ cell effector function. ${ }^{17}$ After binding its natural ligand 4-1BBL, 4-1BB induces intracellular signaling through TNFR-associated factor $2 .{ }^{18}$ Murine glioma models have shown in vivo antitumor activity from treatment with 4-1BB agonists. Radiotherapy combined with anti-4-1BB agonists can induce tumor eradication and prolong survival. ${ }^{19}$ Furthermore, this antitumor response correlates with increased tumor-infiltrating lymphocyte (TIL) density and Interferon gamma (IFNy). The combination of a 4-1BB agonist and a CTLA- 4 inhibitor, plus radiation treatment has also been shown to improve survival and TIL trafficking in an intracranial model. ${ }^{20}$ Interestingly, depletion of CD4 T cells abrogated this effect to an even greater extent than CD8 depletion. Given this preclinical evidence for antitumoral efficacy and immune modulation, 4-1BB represents an attractive target for GBM and indeed is being explored in a clinical trial, NCT02658981, in patients with recurrent GBM.

\section{GITR}

Glucocorticoid-induced tumor necrosis factor (TNF)related receptor (GITR) is highly expressed on T regulatory cells (Tregs) and induced by FOXP3 and NFkB signaling. ${ }^{21}$ Tregs are immunosuppressive lymphocytes which act to inhibit recognition and clearance of tumor cells. ${ }^{22}$ GITR ligand (TNFSF18) is expressed on APC. When GITR binds GITR ligand in concert with TCR stimulation, naïve $T$ cells are activated, eventually leading to NF-kB mediated proliferation and cytokine production such as IL-2 and IFNy. ${ }^{23-25}$ Murine studies have shown that treatment with GITR agonists result in improved survival, increased immune cell infiltrates and robust cytokine production by TILs, but structural and functional differences between murine and human GITR exist. ${ }^{26}{ }^{27}$ One study that evaluated the use of intracranial injections of a GITR agonist found improved overall survival (OS) and selective Treg depletion. ${ }^{28}$ Systemic administration of these anti-GITR monoclonal antibody (mab) had limited effects on mouse survival. Another study combining anti-GITR mab with stereotactic radiosurgery showed increased effector CD4 infiltration, as well as elevated IFNy, IL2, and TNFa production but this did not translate into survival benefit. ${ }^{29}$ The significance of the expression of GITR on Tregs is less clear. One study found no difference in the expression of GITR on peripheral blood cells between patients with GBM and healthy controls. ${ }^{30}$ In contrast, another report suggests that tumor growth upregulates GITR on intratumoral Tregs. ${ }^{31}$ There are multiple early phase trials evaluating GITR, but most are excluding patients with active central nervous system (CNS) metastasis and to date, there are no trials for patients with primary brain tumors. The GITR agonist BMS-986156 has recently demonstrated a favorable safety profile both alone and in combination with nivolumab. In a study of 66 patients, the most common side effect, occurring in $30 \%$, was fever. ${ }^{32}$ A phase I GBM trial, NCT03707457 combining an anti-GITR agent with PD-1 blockade is currently recruiting.

\section{ICOS}

Inducible costimulatory (ICOS) is expressed by T cells following TCR crosslinking and CD28 costimulation. ${ }^{5}$ Through its binding with the ICOS ligand (B7-H2), ICOS plays a role in a variety of immune processes including the regulation of T cell helper cells. The ICOS ligand protein and corresponding mRNA are expressed by gliomas and the neutralization of ICOS ligand subsequently reduces Th1 and Th2 cytokines. ${ }^{33}$ Chimeric antigen receptor (CAR) $\mathrm{T}$ cells targeting ICOS and epidermal growth factor receptor variant III (EGFRvIII) have demonstrated cytotoxicity against glioma (U87) cells in vitro, although concerns about the relevance of the U87 model to human GBM remain. ${ }^{34}{ }^{35}$ These CAR T cells secreted IFNy as determined by cytokine release assay and suppressed tumor growth in a xenograph mouse model.

\section{X40}

OX40 is a transmembrane glycoprotein expressed by Tregs and transiently expressed on T cells following TCR stimulation by viral antigen. ${ }^{36}{ }^{37}$ OX40 agonism inhibits Treg immunosuppression, thereby leading to effector $\mathrm{T}$ cell proliferation. ${ }^{38}$ OX40 ligand is expressed on GBM tumor cells and high levels of OX40L mRNA are associated with prolonged progression-free survival in patients with GBM. ${ }^{39}$ Murine glioma models have shown that OX40 agonists can induce tumor regression and increase TILs. ${ }^{40}$ Similarly, combination immunotherapies have been investigated. One study combining anti-OX40 antibody plus dendritic cell (DC) vaccine plus local cranial 


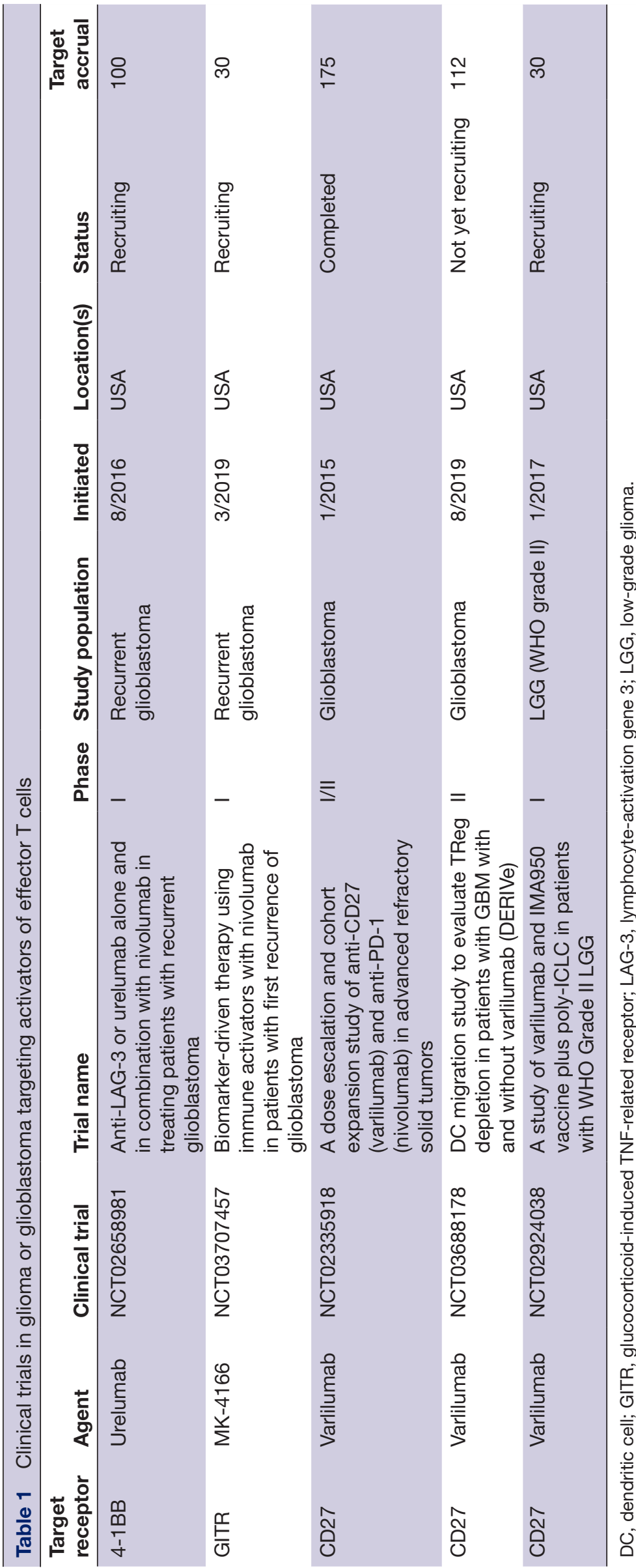




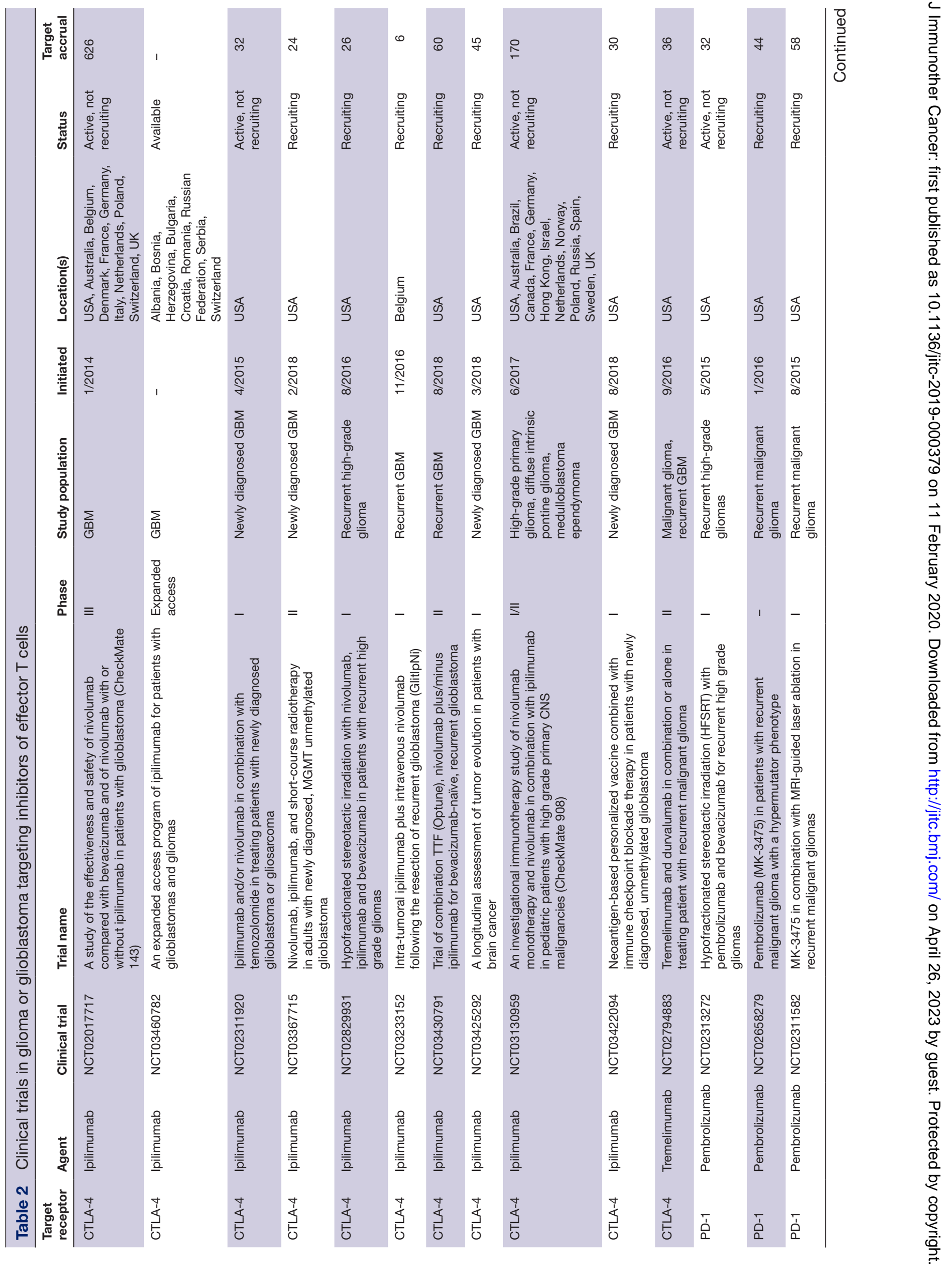




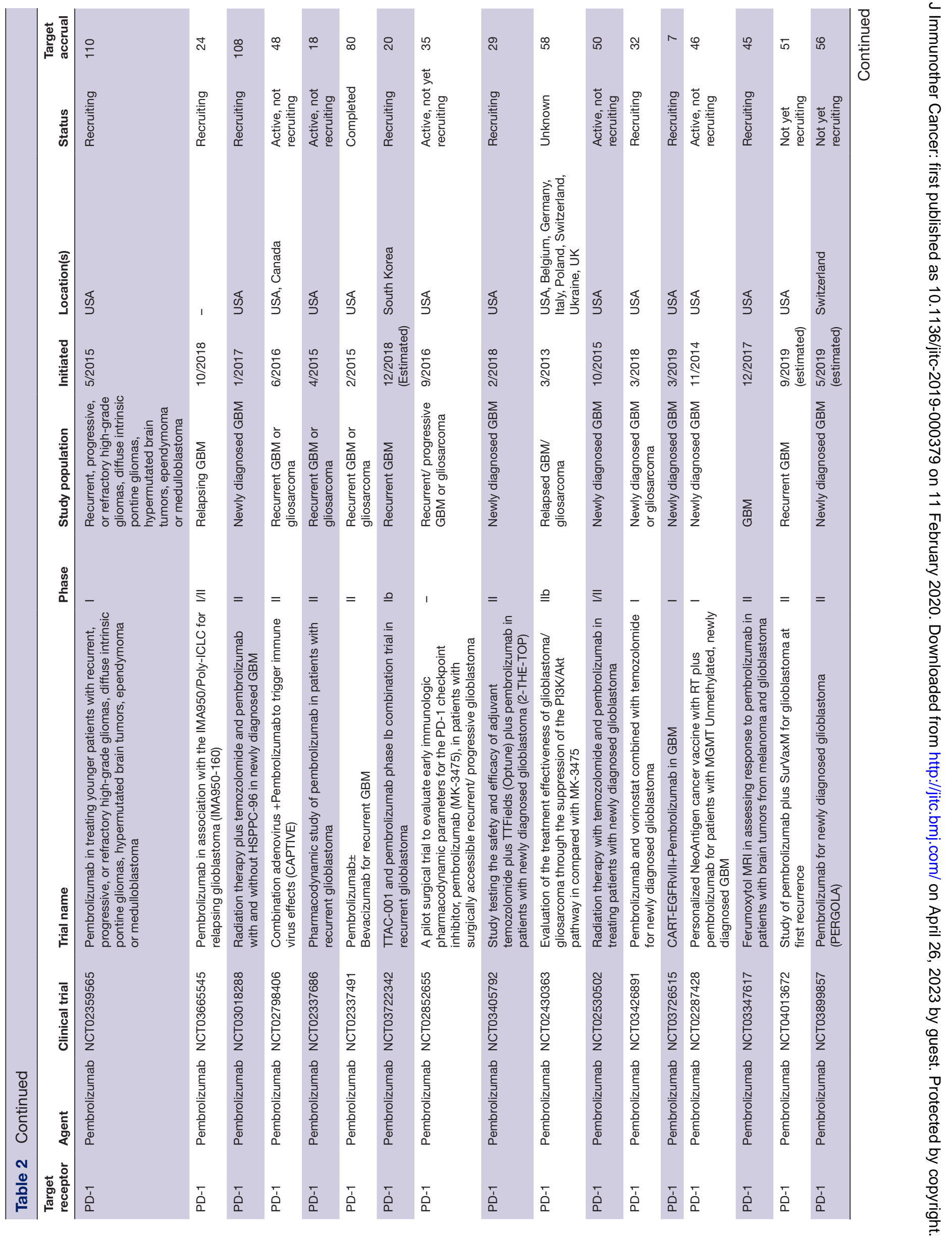




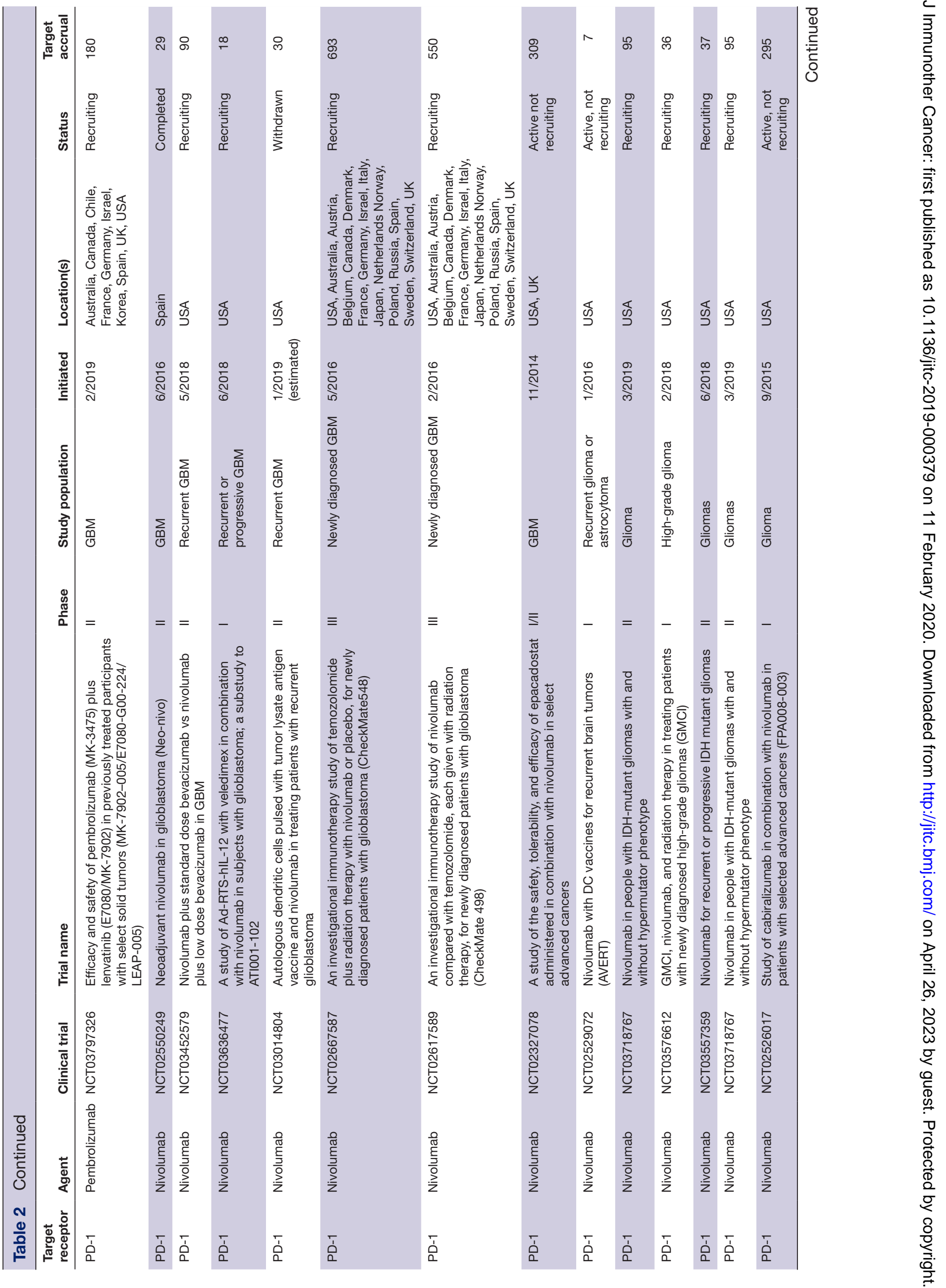




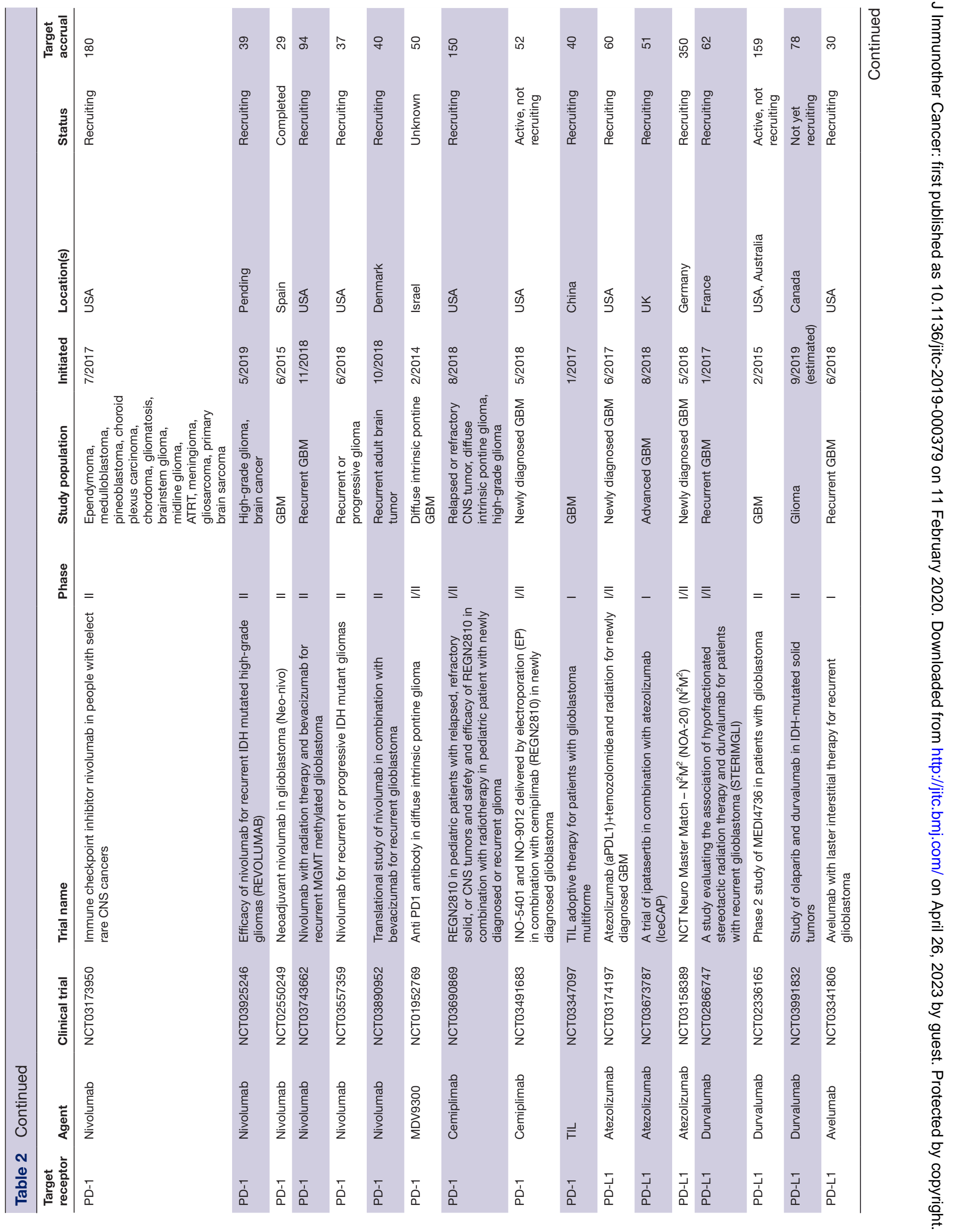




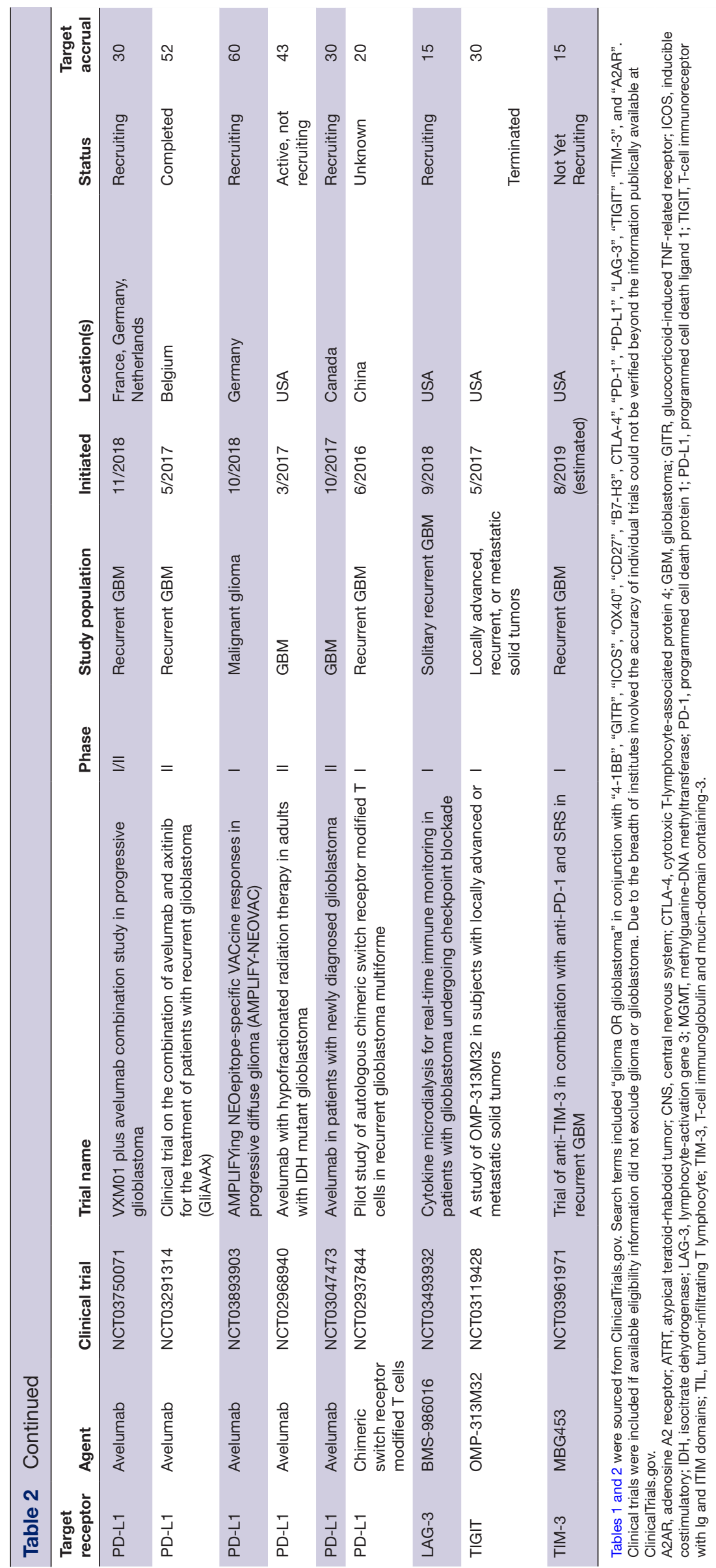


radiation demonstrated tumor regression, TIL infiltration, and improved survival compared with mice treated with only two of the three modalities. ${ }^{41}$ Another study combining granulocyte macrophage colony stimulating factor-expressing cells and an OX40 agonist, showing that the combined therapy promoted Th1 responses while also decreasing Th2 response. ${ }^{42}$ Of note, coexpression of PD-1, TIM-3, and lymphocyte-activation gene 3 (LAG-3) was also reduced.

\section{CD27}

CD27, a member of the TNF receptor family, is expressed on naïve CD4 and CD8 T cells and upregulated with T cell activation. On activation by binding $\mathrm{CD} 70$, a surface antigen expressed on meningioma and glioma cells, ${ }^{43}$ CD27 promotes proliferation by facilitating entry into the cell cycle as well as promoting effector $\mathrm{T}$ cell differentiation. ${ }^{44}$ In vitro studies have shown that glioma cells respond to CD70 signaling. Cell lines engineered to produce soluble CD70 increase proliferation and IFN secretion of cocultured lymphocytes. ${ }^{45}$ Treating in vivo murine glioma models with both a CD70 specific CAR T therapy ${ }^{46}$ and a CD70 antibody-drug conjugate produced tumor regression. ${ }^{47}$ However, other studies have suggested that the CD27 pathway may actually suppress $\mathrm{T}$ lymphocytes. One study found that glioma cells expressing CD70 could induce $\mathrm{T}$ cell apoptosis while simultaneously inhibiting glioma growth. ${ }^{48}$ This finding may be explained by lytic NK activity or a mechanistic difference in the apoptosisregulating Siva pathway between human and mice cells. Furthermore, CD70 overexpression has been shown to increase recruitment of immunosuppressive tumorassociated macrophages. ${ }^{49}$ NCT02924038 is currently examining the CD27 agonist varlilumab in patients with low-grade glioma. Another study, NCT02335918, is looking at the combination of varlilumab with PD-1 blockade among a variety of solid tumors including GBM. Finally, the clinical trial NCT03688178 is investigating varilumab in combination with a DC vaccine and is scheduled to begin soon pending new testing requirements from the FDA.

\section{TARGETING INHIBITORS OF EFFECTOR T CELLS}

Inhibitory checkpoint molecules downregulate $\mathrm{T}$ cell differentiation, proliferation, and activation. Currently, most immune checkpoint inhibitors are antibodies that target these inhibitory molecules. By blocking the interaction of the inhibitory molecules with their ligand immune checkpoint inhibitors, these checkpoint inhibitors prevent suppression of effector $\mathrm{T}$ cells and, in turn, allow for cytotoxic activity. The inhibitory molecules with the most potential for use in clinical trials are reviewed below.

\section{CTLA-4}

Cytotoxic T-lymphocyte-associated protein 4 (CTLA-4) is constitutively expressed on activated Tregs. ${ }^{51}$ Additionally, CTLA-4 expression can be induced on cytotoxic T cells after their stimulation. CTLA-4 competes with the costimulatory molecule CD28 for the CD80 and CD86 ligands (B7-1 and B7-2, respectively), ultimately leading to $\mathrm{T}$ cell inactivation if CTLA-4 engagement predominates. Prognostically, CTLA-4 expression on CD4 and CD8 $\mathrm{T}$ cells may positively correlate with survival in patients with GBM. ${ }^{52}$ Several murine glioma models have shown antitumor efficacy and improved survival using speciesspecific mab blockade of CTLA-4. Although long-term tumor-free survival in mice is only modest with single agent anti-CTLA-4 therapy, combinational studies with anti-PD-1 or anti-PD-L1 have demonstrated cure rates as high as $75 \%{ }^{53}$ CTLA-4 antibody blockade has also been shown to enhance whole tumor-cell vaccine efficacy and improve survival. ${ }^{555}$ In mice treated with a herpes simplex oncolytic virus, the combination of anti-CTLA-4 and anti PD-1 therapy was found to improve survival. ${ }^{56}$ Furthermore, combined with intratumoral administration of IL-12, CTLA-4 inhibitors were shown to cause a reduction in tumor burden, decreasing Tregs and increasing effector T cells. ${ }^{57}$ Several early phase studies are examining CTLA-4 inhibitors in GBM. CheckMate 143, a phase I study of 40 patients with recurrent GBM treated with the PD-1 inhibitor nivolumab, alone or in combination with the CTLA inhibitor ipilimumab, showed a survival of only 7 to 10 months and response rates of $0 \%-11 \% .^{58}$ Additionally, nivolumab did not improve OS when compared with bevacizumab in this population. ${ }^{59}$ There remain several trials studying ipilimumab in conjunction with nivolumab. NCT03367715 is examining nivolumab and ipilimumab in conjunction with short-course radiotherapy. Similarly, NCT02829931 and NCT03425292 combine CTLA-4, PD-1 and bevacizumab with radiation therapy. NCT03233152 is investigating intratumoral administration of ipilimumab in conjunction with nivolumab after resection of recurrent GBM. NCT03430791 uses nivolumab and ipilimumab with tumor-treating fields. NCT03422094 combines dual checkpoint blockade with a personalized neoantigen-based vaccine (NeoVax). The pediatric study, CheckMate 908, is examining ipilimumab and nivolumab in childhood CNS malignancies. NCT02794883 is a study of the CTLA-4 inhibitor tremelimumab plus the PD-1 inhibitor durvalumab in recurrent glioma. Additionally, an expanded access program of ipilimumab is available in countries worldwide although it is currently not available in the USA and many European nations.

\section{PD-1}

PD-1, is expressed on activated T cells. When PD-1 binds its ligand, programmed death ligand 1 (PD-L1), TCR signaling is downregulated, which in turn decreases T cell proliferation and activation. PD-1 has also been implicated in the activation of epithelial-mesenchymal transition ${ }^{60}$ and prevention of Treg expansion in glioma. ${ }^{61}$ Estimates of PD-L1 expression on human GBM have ranged between $19 \%$ and $88 \%$, with some variation ascribed to the technique and antibody use. ${ }^{62-64}$ Prognostically, PD-1 expression on TILS and PD-L1 expression on tumor cells 
both correlate with glioma grade. ${ }^{65}$ Zeng et al, described improved survival in murine models with the combination of PD-1 inhibitor plus radiotherapy ${ }^{66}$ Combining anti-PD-1 with temozolomide, the standard of care for treatment of GBM, produces decreased tumor growth, increased TILs and improved survival when compared with monotherapy. ${ }^{67-69}$ PD-1 blockade combined with oncolytic viral therapy has also been shown to increase survival in mice. ${ }^{70}$ 71 $\mathrm{DC}$ vaccines in combination with PD-1 inhibitors likewise demonstrate improved murine survival. ${ }^{72}$ Finally, the combination of a PD-1 inhibitor and toll-like receptor (TLR-3) agonist therapy increased DC activation and T cell proliferation. ${ }^{73}$ A phase I study of 16 patients with recurrent GBM treated with atezolizumab reported a favorable safety profile but a disappointing median survival of only 4.2 months. ${ }^{74}$ Similarly, the phase I trial KEYNOTE-028 described 26 patients with recurrent PD-L1+GBM treated with pembrolizumab, observing an OS of 14.4 months and objective response rate of only $4 \% \cdot{ }^{75}$ However, a pilot trial of 35 patients with recurrent GBM recently found neoadjuvant pembrolizumab treatment arm to have an OS of 13.7 months, a statistically significant difference to the 7.5 month survival of those receiving adjuvant (post-surgical) pembrolizumab. ${ }^{3}$ While the OS is in keeping with historical expectations, the molecular findings suggest that treatment effect may actually be responsible for the discrepancies between the two cohort arms. In this study, neoadjuvant PD-1 blockade upregulated T-cell- $\gamma$ and IFN- $\gamma$ signals and downregulated cell-cycle-related transcripts. Focal expression of PD-L1 on tumor cells was also inducible by neoadjuvant treatment. TCR sequencing demonstrated enhanced clonal expansion in this cohort as well. A companion paper detailing 30 patients with GBM treated with neoadjuvant nivolumab likewise showed increases in chemokine transcripts, immune infiltration and TCR clonal diversity. ${ }^{76}$ Two patients on this study remained alive over 28 months later. Another study performed genomic and transcriptomic analysis of 66 patients with GBM treated with PD-1 inhibitors, highlighting alterations of PTEN in non-responders and the MAPK pathway in responders. ${ }^{77}$

There are numerous early phase trials examining PD-1 and PD-L1 targeting agents in gliomas, often in conjunction with radiation or bevacizumab. In addition to these, Checkmate 548 and 498 are phase III clinical trials examining checkpoint inhibitor therapy in MGMT methylated and unmethylated populations, respectively. A recent press release from CheckMate498 indicates that the study did not meet its primary endpoint of OS. ${ }^{78}$ NCT03491683 combines a PD-1 inhibitor with an IL-12 and antigen-stimulation strategy delivered by intramuscular injection and electroporation. Another interesting trial, NCT03347097, is examining the use of pluripotent immune killer cells constructed from transgenic-modified TILs to highly express PD-1. Combinational approaches with tyrosine kinase inhibitors (TKI) are also under investigation. GLIAVAX, a phase II trial of 54 patients with recurrent GBM treated with avelumab and axitinib demonstrated favorable tolerability but did not meet the primary endpoint goal with a 6 -month progression-free survival (PFS-6) of only $18 \% .^{79}$ The addition of pembrolizumab to bevacizumab, a VEGF inhibitor, also did not improve PFS- $6 .{ }^{80}$ Other TKI combinations being studied with PD-1 blockade include TTAC-001 (VEGFR-2/KDR) and lenvatinib (VEGFR1/2/3). Small molecule inhibitors such as vorinostate (histone deacetylase inhibitor), ipatasertib (AKT), olaparib (PARP), and epacadostat (indoleamine 2,3-dixoygenase-1) are also being under investigation in GBM. The NCT Neuro Master Match employs molecular characterization and bioinformatic evaluation to stratify patients toward multiple therapeutic arms including atezolizumab. Vaccine combinations currently under investigation include the IMA950 (multipeptide vaccine), HSPPC-96 (heat shock protein peptide complex), DNX-2401 (genetically modified oncolytic adenovirus), SurVaxM (survivin tumor-specific antigen), DCVax-L (autologous DC pulsed with tumor lysate antigen), VXM01 (VEGFR-2 DNA vaccine), NeoVax, and a IDH1 R132H-specific vaccine. Additionally, there are also CAR T strategies targeting EGFRvIII and PD-1. NCT02359565 and NCT03173950 are examining PD-1 inhibitors among rare or pediatric CNS tumors populations. Finally, NCT02311582 and NCT03341806 are studies focused on the effects of PD-1 inhibition in conjunction with MRI-guided laser ablation and laser interstitial thermal therapy, respectively.

\section{LAG-3}

LAG-3 is an immunoglobulin expressed on NK, DC, and $\mathrm{B}$ cells that plays an inhibitory role in $\mathrm{T}$ cell proliferation and cytokine secretion. ${ }^{81}$ In glioma samples analyzed by flow cytometry, $30 \%$ of CD8 TIL express LAG- $3 .{ }^{82}$ Much lower expression (1.25\%) was observed in CD4 TILs. One phase I study, NCT03493932, is examining LAG-3 inhibitor therapy after cytokine microdialysis and tumor resection in patients with recurrent GBM.

\section{TIGIT}

$\mathrm{T}$ cell immunoreceptor with Ig and ITIM domains (TIGIT) is a transmembrane protein which binds to CD155 and inhibits NK cell activity. ${ }^{83}$ TIGIT expression is also found on CD8 T cells, CD4 T cells, Tregs, and NK cells. Pediatric glial tumors contain CD4 and CD8 T cells which express TIGIT as well as TIM3, OX40, and 4-1BB. ${ }^{84}$ Combination treatment with TIGIT and PD-1 blockade was shown to increase cytotoxic CD8 cells, reduce Tregs and improved survival in a murine glioma model. ${ }^{85}$ PD-1 and TIGIT coblockage increased IFNy- and TNFaproducing CD8 (and CD4) T cells as compared with monotherapy groups. Tregs were also decreased but with no significant difference observed between combination and monotherapy groups. Reimplantation of tumor in the surviving animals demonstrated immune memory with no deaths at 90 days compared with a median survival of 21 days in a control group. There are currently no trials of TIGIT agents specifically in glioma or GBM. However, 
NCT03119428 is examining the anti-TIGIT agent OMP313M32 in locally advanced, recurrent or metastatic solid tumor malignancies.

\section{TIM-3}

T-cell immunoglobulin and mucin-domain containing-3 (TIM-3) is present on T cells, DC, macrophages, NK, and tumor cells. On binding galectin-9 and phosphatidylserine, TIM-3 induces $\mathrm{T}$ cell apoptosis, increasing phagocytosis and upregulating proinflammatory cytokine secretion. ${ }^{86}$ TIM-3 also binds carcinoembryonic antigen cell adhesion molecule 1 (CAECAM1) on activated $\mathrm{T}$ cells thereby inhibiting them. ${ }^{86}$ TIM-3 is expressed in higher grade glioma and negatively correlates with T-cellmediated immune responses. ${ }^{87}$ Peripheral T lymphocyte expression of TIM-3 is also increased and correlates with worsened grade. ${ }^{88} 89$ Furthermore, this expression may be even higher in intratumoral effector lymphocytes. ${ }^{90}$ Combined antibody blockade of TIM-3 and its CAECAM ligand have been shown to prolong survival in GBM mouse models. ${ }^{91}$ This therapy increased the ratio of CD4/ CD8 to Tregs among brain-infiltrating lymphocytes (BIL) and selective depletion of these CD4 and CD8 cell extinguished the survival effect. IFNy and TGF- $\beta$ were upregulated and decreased, respectively, reflecting shift in the cytokine milieu. Triple therapy with PD-1 blockade, TIM-3 blockade, and radiation has also been demonstrated to improved survival compared with dual or monotherapy. ${ }^{92}$ Combination therapy also increased the CD8 effector/ Treg ratio, IFN $\gamma$-producing $\mathrm{CD} 4$ cells and IFN $\gamma$-producing CD8 cells. Interestingly, BIL coexpression of PD-1 and TIM-3 were noted to increase with time. This suggests that the natural history of glioma may upregulate TIM-3, representing an immunosuppressive adaptation that can be countered with inhibitors. Following reimplantation, none of these long-term survivors established tumors, thus demonstrating that the mice had achieved immunological memory. A clinical trial, NCT03961971, combining the anti-TIM-3 inhibitor MBG453 with the PD-1 inhibitor spartalizumab and stereotactic radiosurgery is scheduled to begin August 2019.

\section{A2AR}

Adenosine A2 receptor (A2AR) is a $\mathrm{G}$ protein-coupled receptor. Tissue breakdown and hypoxia promote extracellular adenosine production which in turn leads to anti-inflammatory effects mediated by these $G$ proteincoupled receptors. ${ }^{93}$ Increased cyclic AMP upregulates immunosuppressive cytokines, increases PD-1, induces $\mathrm{T}$ cell anergy and promotes Treg differentiation. Taken together, these events create a more immunosuppressive tumor microenvironment. Inhibition of A2AR is, therefore, a potential method to stimulate the immune system. Several purine derivatives related to this have been identified as having in vivo activity against glioma. The surface ectoenzyme CD39 catabolizes proinflammatory ATP into AMP, and glioma cells have been shown to induce CD4 T cell suppression via CD39, an effect which is preventable with the introduction of A2AR antagonists. ${ }^{94}$

\section{B7-H3}

B7-H3, an immunomodulatory protein expressed on both lymphocytes and tumor cells, appears to have a host of complex effects on T lymphocytes. Initial reports of human B7-H3 identified a role in upregulating T cell proliferation, and it was noted that cytotoxicity with antibody blockade of B7-H3, or its potential ligand TLT-2, in turn suppresses $\mathrm{T}$ cell activation. ${ }^{95}{ }^{96}$ However, more recent experiments of murine B7-H3 conversely suggest that B7-H3 may actually have suppressive effects on cytotoxic $\mathrm{T}$ cells by downregulating proinflammatory $\mathrm{Th} 1$ cells. $^{97}{ }^{98}$ B7-H3 expression in glioma correlates with higher grade and worsened prognosis. ${ }^{99} 100$ One study in murine glioma models found that B7-H3 gene silencing of B7-H3 leads to a less invasive phenotype. ${ }^{101}$ Together, these suggest that B7-H3 upregulation promotes tumor growth and invasion which, if true, could be through immune or non-immune related mechanisms.

\section{VISTA}

V-domain Ig suppressor of T cell activation (VISTA), also known as PD-1H, is an inhibitory molecule expressed on hematopoietic cells and tumor cells. On binding an unknown receptor VISTA suppresses CD4 and CD8 T cell activation and promotes Treg proliferation. ${ }^{102} 103$ In murine glioma models (GL261), VISTA knockout was shown to prolong survival and synergism with radiation was observed. ${ }^{104}$ VISTA is not currently being studied in human trials.

\section{B7-H4}

There are a host of other immune checkpoint molecules which have been shown to influence the tumor microenviroment but remain early in development. B7-H4 (B7S1) is an inhibitory molecule expressed on APC which inhibits T cells. ${ }^{105} 106$ Additionally, B7-H4 is expressed by glioma stem-like cells (U251). ${ }^{107}$ B7-H4 expression has been shown to be associated with prognosis in GBM where it appears to mediate cross talk between glioma and macrophages via the IL-6/STAT3 signaling pathway. ${ }^{108}$ Other checkpoint molecules such as B and T lymphocyte attenuator (BTLA) have yet to be sufficiently described in glioma.

\section{ALTERNATIVE MECHANISMS OF IMMUNE MODULATION FOR T LYMPHOCYTE ACTIVATION}

To date, the success of targeting immune modulatory molecules has been by using monoclonal antibodies that block either ligand or receptor. However, multiple other mechanisms of targeting these interactions are also under development.

In contrast to monoclonal antibodies, small molecule inhibitors contain only sufficient chemical structures needed to antagonize target molecules. Small molecule 
inhibitors would conceivably possess greater molecular stability, less immunogenicity and improved penetration to tumor sites than monoclonal antibodies. The ability to more easily penetrate the BBB makes these small molecule inhibitors particularly attractive for the treatment of glioma. The PD-1/PD-L1 binding site has been characterized as hydrophobic and spatially flat. ${ }^{109}$ To this end, various compounds have been developed that specifically block the PD-1/PD-L1 interaction. ${ }^{110}$ These compounds consist of a core scaffold of either three aromatic rings or two and a benzodioxan ring with additional variant moieties. They have been shown to bind PD-L1 and block the interaction of PD-1 as verified by the restoration of $15 \mathrm{~N}$ resonance signal on radiolabeled PD-1. ${ }^{111}$ The $\mathrm{EC}_{50}$ of the least toxic compounds BMS-1001 and BMS-1116 was 33.4 and $40.5 \mathrm{uM}$, respectively. These compounds were shown to induce TCR stimulation, as measured by a luciferase reporter gene. Crystallography demonstrated that BMS-1166 showed four protein bonds with a dimer complex of PD-L1. Furthermore, four decompensation fragments, representing the core aromatic and benzodioxan structures, displayed PD-L1 affinity.

Typical monoclonal antibodies are $\sim 150 \mathrm{kDa}$ in weight and consist of two heavy and two light protein chains, as well as Fab and single-chain variable fragments. Nanobodies, also called single-domain antibodies, are recombinant antibody fragments containing a monomeric antigen-binding domain. Nanobodies are only $\sim 15 \mathrm{kDa}$, more hydrophilic, more stable and less sterically hindered then their full antibody counterparts, drastically improving their ability to penetrate into tumor and molecular sites. ${ }^{112-114}$ Furthermore, these nanobodies can be humanized to further decrease their immunogenicity. ${ }^{115}$ Various delivery systems for immune checkpoint modulators, including platelet, viral and bacterial vectors are also under active investigation. ${ }^{116}$ Caplacizumab, a nanobody targeting von Willebrand factor, recently received the first ever FDA approval for a nanobodydirected therapy. ${ }^{117} \mathrm{KN} 035$, an anti-PD-L1 IgV-type nanobody has been shown to bind chiefly through a 21 amino acid segment that includes the Ile54, Tyr56 and Arg113 residues which participate in the PD-1 interaction. ${ }^{118}$ Notably, KN035 affinity for PD-L1 is 1000 -fold stronger than PD-1's affinity for PD-L1 $\left(\mathrm{IC}_{50}=5.25 \mathrm{nM}\right) .{ }^{119}$

CAR T cells, T cells genetically engineered with MHCindependent recognition of tumor-associated antigens (TAA), have shown increasing benefit in the treatment of hematological malignancy. ${ }^{120} 121$ CAR T cells with antiPD-L1 targeting have demonstrated cytotoxic activity in mice bearing melanoma and colon tumors. ${ }^{122}$ In addition, CAR T cells have been developed with a switch receptor construct composed of extracellular PD-1 domains coupled to transmembrane and cytoplasmic CD28 signaling domains. ${ }^{123}$ These CAR T cells have been shown to induce tumor regression in murine models of prostate cancer. CAR T cells have also been engineered to secrete PD-L1 antibody. In orthotropic renal cell cancer models, these CAR T cells were capable of inhibiting tumor growth via T-cell exhaustion and NK cell recruitment. ${ }^{124}$

Using vaccine therapy to induce $\mathrm{T}$ lymphocyte activation is another approach. Tumor vaccines are intended to provoke an adaptive immune response to TAA whereby these TAA are presented by MHC I/II on APC for recognition by naïve $\mathrm{T}$ cells which then proliferate and differentiate into cytotoxic $\mathrm{T}$ lymphocytes with specificity for tumors expressing said TAA. ${ }^{25}$ Several vaccine types exist including peptide-based, heat-shock protein and DC vaccines.

Peptide vaccines consist of TAA extracted from tumor tissue or synthesized from known epitopes. Some of the epitopes frequently employed in GBM-targeting peptide vaccines include melanoma-associated antigen 1 (MAGE1), human epidermal growth factor receptor 2 (HER2) and gp100. ${ }^{126}$ They are frequently administered with an immunostimulatory adjuvant such as a TLR agonist. There have been several studies targeting the epidermal growth factor receptor variant III, a transmembrane tyrosine kinase receptor variant which is expressed in 24\%-67\% of GBM. ${ }^{127} 128$ Phase II studies (ACTIVATE, ReACT) of EGFRVIII specific peptide initially showed promising OS in the newly diagnosed and recurrent settings, respectively. ${ }^{129}{ }^{130}$ However, ACTIV, a phase III of 745 patients with newly diagnosed EGFRvIII+GBM treated with CDX-110 and GM-CSF showed no OS advantage over control. ${ }^{131}$ Another approach has been to use intratumor delivery of recombinant polio-rhinovirus chimera, PVSRIPO. PVSRIPO binds with high affinity to poliovirus receptor (CD155) which is highly expressed on malignant glioma. ${ }^{132}$ A phase I trial of 61 patients with recurrent GBM showed a median OS of 12.5 months. ${ }^{133}$

Heat-shock vaccines combine TAA with chaperone heat shock proteins (HSP). HSP are involved in posttranslational protein folding as well as modulation of the immune response. ${ }^{134-136}$ HSP complex with TAA and then internalized into APC via receptor-mediated endocytosis, via CD91 and LOX-1, for presentation to CD8+ T cells by MHC I. ${ }^{137-139}$ Additionally, HSP can trigger an innate immune response through TLR. ${ }^{140}$ Phase II results of 41 patients with recurrent GBM treated with a $96 \mathrm{kD}$ HSP protein complex, HSPPC-96, showed a median OS of 42.6 weeks. ${ }^{141}$ NCT03018288 is an ongoing randomized, double-blind phase II trial of surgery, chemoradiation, and pembrolizumab with and without HSPPC-96 in newly diagnosed MGMT unmethylated GBM.

DC vaccines use professional APC which participate in the innate immune response. ${ }^{142}$ On internalization of antigen, DC migrate to lymphoid tissue where they stimulate CD4 and CD8 T cells. The VICTORI study, a trial of 20 patients with newly diagnosed grade III/IV glioma treated with autologous DC vaccine (DC pulsed with EGFRvIII peptide conjugated to keyhole limpet haemocyanin) showed an OS of 22.8 months from diagnosis. ${ }^{143}$ A significant increase in antigen-specific $\mathrm{T}$ cell proliferation was observed in postvaccination peripheral blood. Another phase I, ICT-107, treated 20 patients with GBM 
(and 1 brainstem glioma) with a multiepitope-pulsed DC vaccine (HER2, TRP-2, gp100, MAG-1, IL13Ra2, AIM-2) observing a median OS of 38.4 months with expression of target epitopes (MAGE-1, AIM-2) correlating with improved survival. ${ }^{126}$ Other trials with smaller patient cohorts have shown long-term response and correlative immune response. ${ }^{144}$ Finally, a comparison of 6 patients with malignant glioma treated with glioma-associated antigen compared with 28 patients treated with autologous tumor lysate-pulsed DC vaccine showed elevated NK activity in the glioma-associated antigen cohort. ${ }^{145}$ Additionally, decreased T reg ratio and activated NK cells correlated with prolonged survival in these patients.

\section{CONCLUSION}

The development of PD-1, CTLA-4 and newer, "second generation" checkpoint modulators represents a potential opportunity to develop novel therapies for the treatment of primary brain tumors, particularly GBM. Unfortunately, there are currently limited data on immune checkpoint inhibitors in other types of glioma such as oligodendroglioma or astrocytoma. As these diseases tend to have a more indolent, although still malignant course, it is feasible that immune surveillance aided by checkpoint modulation could fair better than the more proliferative and aggressive GBM. A series of 10 patients with recurrent or refractory pediatric brain tumors including pineoblastoma, medulloblastoma, ependymoma and CNS embryonal showed transient partial responses in patients with PD-L1 expression and higher tumor mutation burden. ${ }^{146}$ A study of the immune checkpoint inhibitor nivolumab is ongoing in patients with select rare CNS cancers (NCT03173950). Additionally, responses to immune checkpoint blockade have been reported, although rarely, in other primary CNS malignancies such as meningioma and primary CNS lymphoma ${ }^{147-149}$

Initial studies using single agent immune modulators in GBM have been mostly unsuccessful, thereby providing a stronger rationale for the consideration of combinational regimens. However, as outlined in this review, there are many candidate agents, which when considered for combination regimens, yield an impractical number of dual agent treatment regimens. Therefore, increased understanding of the mechanisms of action and resistance combined with more robust preclinical and early clinical testing will be needed to be able to adequately test the most promising therapies.

Among the activating immune checkpoint molecules, the ones with the most robust preclinical data are 4-1BB and GITR. Agonists against both these targets have demonstrated antitumoral activity and alteration of the cellular milieu in murine glioma models. They have both also proven to be synergistic with radiotherapy in mice, a particularly attractive feature as radiotherapy remains the mainstay of treatment for newly diagnosed GBM. GITR is also of interest in that, as its name suggests, it is upregulated by glucocorticoids. ${ }^{150}$ Given the high prevalence of steroid use in patients with GBM, GITR may be overexpressed on the TILs of these patients. Although corticosteroids blunt the immune response of checkpoint modulators, upregulation of GITR with the addition of a robust GITR agonist may have an antitumor effect even in the presence of steroids. Furthermore, intracranial administration of GITR may be necessary to provoke an immune response. Given the available preclinical data, further early phase clinical trials to demonstrate safety and efficacy of these agonists in glioma are needed.

Other activating immune molecules including ICOS, OX40, and CD27 need further study in glioma mice models, specifically intracranial models, to demonstrate that agents targeting these molecules produce tumor regression, immune modulation, and improved survival. Preclinical work suggests combining OX40 agonists with vaccine therapies would likely be of most benefit. Cellular and antibody therapies directed against CD27 and its ligand CD70 have shown tumor inhibition in mice. However, contradictory preclinical findings have called into question whether $\mathrm{CD} 27$ and $\mathrm{B} 7-\mathrm{H} 3$ signaling plays a protumoral or antitumoral role in the immune system and more work is needed to elucidate if the antitumoral effect initially observed is indeed $\mathrm{T}$ lymphocyte mediated.

The inhibitory immune checkpoint molecules PD-1 and CTLA-4 are under active investigation with a recent study suggesting efficacy from PD-1 inhibitors when given preoperatively. This is consistent with the efficacy observed in early phase studies of Merkel cell, bladder, and triple negative breast cancer, suggesting that neoadjuvant treatment is a viable immunomodulatory approach. ${ }^{151}$ Other modulatory strategies may also have utility. TIM-3 antibody blockade improves survival and, like 4-1BB and GITR, appears to have synergistic benefit with radiation in mice models. TIM-3 studies have also shown immunomodulation with increased immune cell infiltration, activation, and memory. Similarly, TIGIT, in combination with PD-1 blockade has demonstrated improved survival as well as increased cytotoxicity and decreased regulatory T cells. Both TIM-3 and TIGIT may be good candidates for phase I/II trials in patients with glioma. In contrast, the physiological mechanisms regarding LAG-3, A2AR, VISTA, and B7-H4 in glioma remain unclear and both targets would likely benefit from further preclinical studies to better define efficacy as well as their immunomodulatory effects. Similarly, conflicting findings exist for B7-H3, mandating additional research to elucidate the effect of B7-H3 blockade on different T cell subpopulations and associated tumor response before its consideration for clinical trial testing.

The function of immunomodulatory molecules such as those described here can be activated or inhibited by mab binding and this has to date proved to be the most successful approach. However, several other mechanisms for regulation exist, each with their own advantages and disadvantages. Small molecule inhibitors such as BMS-1166 could reach to molecular sites that larger antibodies cannot access due to steric hindrance. Nanobodies, 
like KN035 can bind PD-L1 with great affinity. Furthermore, delivery systems such as viral vectors may improve BBB infiltration of nanobodies. CAR T cells hold great potential due to the range of genetic modifications (chimeric switch-receptors, antibody secretion) currently under development. Finally, vaccine therapy can prime cytotoxic and helper $\mathrm{T}$ cells for a more robust immune response.

In conclusion, the development of several novel immune checkpoint molecules represents a potential mechanism to overcome the immunosuppressive environment of GBM and achieve meaningful benefit. Of these "second generation" checkpoint molecules, the ones with the greatest potential and most preclinical data in glioma, are 4-1BB, GITR, TIM-3, and TIGIT. All of which should be considered for early phase clinical trials in glioma.

Acknowledgements We would like to acknowledge Chun Zhang Yang for his guidance regarding the U87 model.

Contributors WJK drafted the initial manuscript. AJG assisted with design and scientific review. MG provided concept and interpretation of scientific data. All authors contributed to manuscript editing, proofread and have approved the final manuscript.

Funding The authors have not declared a specific grant for this research from any funding agency in the public, commercial or not-for-profit sectors.

Competing interests None declared.

Patient consent for publication Not required.

Provenance and peer review Not commissioned; externally peer reviewed.

Open access This is an open access article distributed in accordance with the Creative Commons Attribution Non Commercial (CC BY-NC 4.0) license, which permits others to distribute, remix, adapt, build upon this work non-commercially, and license their derivative works on different terms, provided the original work is properly cited, appropriate credit is given, any changes made indicated, and the use is non-commercial. See http://creativecommons.org/licenses/by-nc/4.0/.

\section{REFERENCES}

1 Johnson DB, Sullivan RJ, Menzies AM. Immune checkpoint inhibitors in challenging populations. Cancer 2017;123:1904-11.

2 Bouffet E, Larouche V, Campbell BB, et al. Immune checkpoint inhibition for Hypermutant glioblastoma multiforme resulting from germline biallelic mismatch repair deficiency. J Clin Oncol 2016;34:2206-11.

3 Cloughesy TF, Mochizuki AY, Orpilla JR, et al. Neoadjuvant antiPD-1 immunotherapy promotes a survival benefit with intratumoral and systemic immune responses in recurrent glioblastoma. Nat Med 2019;25:477-86.

4 Weller M, Kleihues P, Dichgans J, et al. CD95 ligand: lethal weapon against malignant glioma? Brain Pathol 1998;8:285-93.

5 Wikenheiser DJ, Stumhofer JS. ICOS co-stimulation: friend or foe? Front Immunol 2016;7:304.

6 Wiendl $\mathrm{H}$, Mitsdoerffer M, Hofmeister $\mathrm{V}$, et al. A functional role of HLA-G expression in human gliomas: an alternative strategy of immune escape. J Immunol 2002;168:4772-80.

7 Frei K, Gramatzki D, Tritschler I, et al. Transforming growth factor- $\beta$ pathway activity in glioblastoma. Oncotarget 2015;6:5963-77.

8 Gabrilovich DI, Chen HL, Girgis KR, et al. Production of vascular endothelial growth factor by human tumors inhibits the functional maturation of dendritic cells. Nat Med 1996;2:1096-103.

9 Bloch O, Crane CA, Kaur R, et al. Gliomas promote immunosuppression through induction of $\mathrm{B} 7-\mathrm{H} 1$ expression in tumor-associated macrophages. Clin Cancer Res 2013;19:3165-75.

10 Goldberg SB, Gettinger SN, Mahajan A, et al. Pembrolizumab for patients with melanoma or non-small-cell lung cancer and untreated brain metastases: early analysis of a non-randomised, open-label, phase 2 trial. Lancet Oncol 2016;17:976-83.

11 Tawbi HA, Forsyth PA, Algazi A, et al. Combined nivolumab and ipilimumab in melanoma metastatic to the brain. N Engl J Med 2018;379:722-30.
12 Long GV, Atkinson V, Lo S, et al. Combination nivolumab and ipilimumab or nivolumab alone in melanoma brain metastases: a multicentre randomised phase 2 study. Lancet Oncol 2018:19:672-81.

13 Kipnis J. Multifaceted interactions between adaptive immunity and the central nervous system. Science 2016;353:766-71.

14 Schläger C, Körner H, Krueger M, et al. Effector T-cell trafficking between the leptomeninges and the cerebrospinal fluid. Nature 2016;530:349-53.

15 Giles AJ, Hutchinson M-KND, Sonnemann HM, et al. Dexamethasone-Induced immunosuppression: mechanisms and implications for immunotherapy. J Immunother Cancer 2018;6:51

16 Olnes MJ, Kotliarov Y, Biancotto A, et al. Effects of systemically administered hydrocortisone on the human Immunome. Sci Rep 2016;6:23002.

17 Chester C, Sanmamed MF, Wang J, et al. Immunotherapy targeting 4-1BB: mechanistic rationale, clinical results, and future strategies. Blood 2018:131:49-57.

18 Vinay DS, Kwon BS. 4-1BB (CD137), an inducible costimulatory receptor, as a specific target for cancer therapy. BMB Rep 2014;47:122-9.

19 Newcomb EW, Lukyanov Y, Kawashima N, et al. Radiotherapy enhances antitumor effect of anti-CD137 therapy in a mouse glioma model. Radiat Res 2010;173:426-32.

20 Belcaid Z, Phallen JA, Zeng J, et al. Focal radiation therapy combined with 4-1BB activation and CTLA-4 blockade yields longterm survival and a protective antigen-specific memory response in a murine glioma model. PLoS One 2014;9:e101764.

21 Knee DA, Hewes B, Brogdon JL. Rationale for anti-GITR cancer immunotherapy. Eur J Cancer 2016;67:1-10.

22 Hsieh C-S, Lee H-M, Lio C-WJ. Selection of regulatory T cells in the thymus. Nat Rev Immunol 2012;12:157-67.

23 Tone M, Tone Y, Adams E, et al. Mouse glucocorticoid-induced tumor necrosis factor receptor ligand is costimulatory for T cells. Proc Natl Acad Sci U S A 2003;100:15059-64.

24 Kanamaru F, Youngnak P, Hashiguchi M, et al. Costimulation via glucocorticoid-induced TNF receptor in both conventional and CD25+ regulatory CD4 ${ }^{+} T$ cells. J Immunol 2004;172:7306-14.

25 Ronchetti S, Zollo O, Bruscoli S, et al. GITR, a member of the TNF receptor superfamily, is costimulatory to mouse T lymphocyte subpopulations. Eur J Immunol 2004;34:613-22.

26 Nocentini G, Ronchetti S, Petrillo MG, et al. Pharmacological modulation of GITRL/GITR system: therapeutic perspectives. $\mathrm{Br} J$ Pharmacol 2012;165:2089-99.

27 Ronchetti S, Ricci E, Petrillo MG, et al. GlucocorticoidInduced tumour necrosis factor receptor-related protein: a key marker of functional regulatory T cells. J Immunol Res 2015;2015:171520:1-17.

28 Miska J, Rashidi A, Chang AL, et al. Anti-GITR therapy promotes immunity against malignant glioma in a murine model. Cancer Immunol Immunother 2016;65:1555-67.

29 Patel MA, Kim JE, Theodros D, et al. Agonist anti-GITR monoclonal antibody and stereotactic radiation induce immune-mediated survival advantage in murine intracranial glioma. $J$ Immunother Cancer 2016;4:28.

30 Vasco C, Canazza A, Rizzo A, et al. Circulating T regulatory cells migration and phenotype in glioblastoma patients: an in vitro study. $J$ Neurooncol 2013;115:353-63.

31 Grauer OM, Nierkens S, Bennink E, et al. Cd4+Foxp3+ regulatory $\mathrm{T}$ cells gradually accumulate in gliomas during tumor growth and efficiently suppress antiglioma immune responses in vivo. Int $J$ Cancer 2007:121:95-105.

32 Siu LL SN, Meniawy T, et al. Preliminary results of a phase I/Ila study of BMS-986156 (glucocorticoid-induced tumor necrosis factor receptor-related gene [GITR] agonist), alone and in combination with nivolumab in pts with advanced solid tumors. $J$ Clin Oncol 2017;35(15 Suppl):104.

33 Schreiner B, Wischhusen J, Mitsdoerffer M, et al. Expression of the B7-related molecule ICOSL by human glioma cells in vitro and in vivo. Glia 2003;44:296-301.

34 Shen C-J, Yang Y-X, Han EQ, et al. Chimeric antigen receptor containing ICOS signaling domain mediates specific and efficient antitumor effect of T cells against EGFRvIll expressing glioma. $J$ Hematol Oncol 2013;6:33.

35 Allen M, Bjerke M, Edlund $\mathrm{H}$, et al. Origin of the U87MG glioma cell line: good news and bad news. Sci Trans/ Med 2016;8:354re3.

36 Gramaglia I, Weinberg AD, Lemon M, et al. Ox-40 ligand: a potent costimulatory molecule for sustaining primary CD4 T cell responses. J Immunol 1998;161:6510-7.

37 Boettler T, Moeckel F, Cheng Y, et al. Ox40 facilitates control of a persistent virus infection. PLoS Pathog 2012;8:e1002913. 
38 Valzasina B, Guiducci C, Dislich H, et al. Triggering of OX40 (CD134) on CD4(+)CD25+ T cells blocks their inhibitory activity: a novel regulatory role for OX40 and its comparison with GITR. Blood 2005:105:2845-51.

39 Shibahara I, Saito R, Zhang R, et al. Ox40 ligand expressed in glioblastoma modulates adaptive immunity depending on the microenvironment: a clue for successful immunotherapy. $\mathrm{Mol}$ Cancer 2015;14:41

40 Kjaergaard J, Tanaka J, Kim JA, et al. Therapeutic efficacy of OX-40 receptor antibody depends on tumor immunogenicity and anatomic site of tumor growth. Cancer Res 2000;60:5514-21.

41 Kjaergaard J, Wang L-X, Kuriyama $\mathrm{H}$, et al. Active immunotherapy for advanced intracranial murine tumors by using dendritic celltumor cell fusion vaccines. J Neurosurg 2005;103:156-64.

42 Jahan N, Talat H, Curry WT. Agonist OX40 immunotherapy improves survival in glioma-bearing mice and is complementary with vaccination with irradiated GM-CSF-expressing tumor cells. Neuro Oncol 2018;20:44-54.

43 Held-Feindt J, Mentlein R. CD70/CD27 ligand, a member of the TNF family, is expressed in human brain tumors. Int. J. Cancer 2002;98:352-6.

44 van de Ven K, Borst J. Targeting the T-cell co-stimulatory CD27/ CD70 pathway in cancer immunotherapy: rationale and potential. Immunotherapy 2015;7:655-67.

45 Miller J, Eisele G, Tabatabai G, et al. Soluble CD70: a novel immunotherapeutic agent for experimental glioblastoma. $J$ Neurosurg 2010;113:280-5.

46 Jin L, Ge H, Long Y, et al. CD70, a novel target of CAR T-cell therapy for gliomas. Neuro Oncol 2018;20:55-65.

47 McDonagh CF, Kim KM, Turcott E, et al. Engineered anti-CD70 antibody-drug conjugate with increased therapeutic index. Mol Cancer Ther 2008;7:2913-23.

48 Aulwurm S, Wischhusen J, Friese M, et al. Immune stimulatory effects of CD70 override CD70-mediated immune cell apoptosis in rodent glioma models and confer long-lasting antiglioma immunity in vivo. Int J Cancer 2006;118:1728-35.

$49 \mathrm{Ge} \mathrm{H}$, Mu L, Jin L, et al. Tumor associated CD70 expression is involved in promoting tumor migration and macrophage infiltration in GBM. Int J Cancer 2017;141:1434-44.

50 Takahashi T, Tagami T, Yamazaki S, et al. Immunologic selftolerance maintained by CD25(+)CD4(+) regulatory T cells constitutively expressing cytotoxic $\mathrm{T}$ lymphocyte-associated antigen 4. J Exp Med 2000;192:303-10.

51 Wing K, Onishi Y, Prieto-Martin P, et al. CTLA-4 control over Foxp3+ regulatory T cell function. Science 2008;322:271-5.

52 Fong B, Jin R, Wang X, et al. Monitoring of regulatory T cell frequencies and expression of CTLA- 4 on T cells, before and after DC vaccination, can predict survival in GBM patients. PLoS One 2012;7:e32614.

53 Reardon DA, Gokhale PC, Klein SR, et al. Glioblastoma eradication following immune checkpoint blockade in an orthotopic, immunocompetent model. Cancer Immunol Res 2016;4:124-35.

54 Field CS, Hunn MK, Ferguson PM, et al. Blocking CTLA-4 while priming with a whole cell vaccine reshapes the oligoclonal $\mathrm{T}$ cell infiltrate and eradicates tumors in an orthotopic glioma model. Oncoimmunology 2018;7:e1376154.

55 Agarwalla P, Barnard Z, Fecci P, et al. Sequential immunotherapy by vaccination with GM-CSF-expressing glioma cells and CTLA- 4 blockade effectively treats established murine intracranial tumors. $J$ Immunother 2012;35:385-9.

56 Saha D, Martuza RL, Rabkin SD. Macrophage polarization contributes to glioblastoma eradication by combination Immunovirotherapy and immune checkpoint blockade. Cancer Cell 2017;32:253-67.

57 Vom Berg J, Vrohlings M, Haller S, et al. Intratumoral IL-12 combined with CTLA-4 blockade elicits T cell-mediated glioma rejection. J Exp Med 2013;210:2803-11.

58 Omuro A, Vlahovic G, Lim M, et al. Nivolumab with or without ipilimumab in patients with recurrent glioblastoma: results from exploratory phase I cohorts of CheckMate 143. Neuro Oncol 2018;20:674-86.

59 Reardon DA, Omuro A, Brandes AA, et al. OS10.3 randomized phase 3 study evaluating the efficacy and safety of nivolumab vs bevacizumab in patients with recurrent glioblastoma: CheckMate 143. Neuro Oncol 2017;19:iii21.

60 Qiu XY, Hu DX, Chen W-Q, et al. PD-L1 confers glioblastoma multiforme malignancy via Ras binding and Ras/Erk/EMT activation. Biochim Biophys Acta Mol Basis Dis 2018;1864:1754-69.

61 DiDomenico J, Lamano JB, Oyon D, et al. The immune checkpoint protein PD-L1 induces and maintains regulatory T cells in glioblastoma. Oncoimmunology 2018;7:e1448329.
62 Berghoff AS, Kiesel B, Widhalm G, et al. Programmed death ligand 1 expression and tumor-infiltrating lymphocytes in glioblastoma. Neuro Oncol 2015;17:1064-75.

63 Xiu J, Piccioni D, Juarez T, et al. Multi-platform molecular profiling of a large cohort of glioblastomas reveals potential therapeutic strategies. Oncotarget 2016;7:21556-69.

64 Xue S, Hu M, lyer V, et al. Blocking the PD-1/PD-L1 pathway in glioma: a potential new treatment strategy. $J$ Hematol Oncol 2017:10:81.

65 Garber ST, Hashimoto Y, Weathers S-P, et al. Immune checkpoint blockade as a potential therapeutic target: surveying CNS malignancies. Neuro Oncol 2016;18:1357-66.

66 Zeng J, See AP, Phallen J, et al. Anti-PD-1 blockade and stereotactic radiation produce long-term survival in mice with intracranial gliomas. Int J Radiat Oncol Biol Phys 2013;86:343-9.

67 Dai B, Qi N, Li J, et al. Temozolomide combined with PD-1 antibody therapy for mouse orthotopic glioma model. Biochem Biophys Res Commun 2018;501:871-6.

68 Mathios D, Kim JE, Mangraviti A, et al. Anti-PD-1 antitumor immunity is enhanced by local and abrogated by systemic chemotherapy in GBM. Sci Transl Med 2016;8:370ra180.

69 Park J, Kim CG, Shim J-K, et al. Effect of combined anti-PD-1 and temozolomide therapy in glioblastoma. Oncoimmunology 2019;8:e1525243.

70 Samson A, Scott KJ, Taggart D, et al. Intravenous delivery of oncolytic reovirus to brain tumor patients immunologically primes for subsequent checkpoint blockade. Sci Transl Med 2018;10:eaam7577.

71 Hardcastle J, Mills L, Malo CS, et al. Immunovirotherapy with measles virus strains in combination with anti-PD-1 antibody blockade enhances antitumor activity in glioblastoma treatment. Neuro Oncol 2017;19:493-502.

72 Antonios JP, Soto H, Everson RG, et al. PD-1 blockade enhances the vaccination-induced immune response in glioma. JCl Insight 2016;1.

73 Garzon-Muvdi T, Theodros D, Luksik AS, et al. Dendritic cell activation enhances anti-PD-1 mediated immunotherapy against glioblastoma. Oncotarget 2018;9:20681-97.

74 Lukas RV, Rodon J, Becker K, et al. Clinical activity and safety of atezolizumab in patients with recurrent glioblastoma. J Neurooncol 2018;140:317-28

75 Reardon DA, Kim T-M, Frenel J-S, et al. ATIM-35. Results of the phase lb KEYNOTE-028 multi-cohort trial of pembrolizumab monotherapy in patients with recurrent PD-L1-positive glioblastoma multiforme (GBM). Neuro Oncol 2016;18:vi25-6.

76 Schalper KA, Rodriguez-Ruiz ME, Diez-Valle R, et al. Neoadjuvant nivolumab modifies the tumor immune microenvironment in resectable glioblastoma. Nat Med 2019;25:470-6.

77 Zhao J, Chen AX, Gartrell RD, et al. Immune and genomic correlates of response to anti-PD-1 immunotherapy in glioblastoma. Nat Med 2019;25:462-9.

78 Bristol-Myers Squibb. Bristol-Myers Squibb Announces phase 3 CheckMate -498 study did not meet primary endpoint of overall survival with Opdivo (nivolumab) plus radiation in patients with newly diagnosed MGMT-Unmethylated glioblastoma multiforme.

79 Neyns B, Ben Salama L, Awada G, et al. GLIAVAX: a stratified phase II clinical trial of avelumab and axitinib in patients with recurrent glioblastoma. J Clin Oncol 2019;37:2034.

80 Reardon DA, Nayak L, Peters KB, et al. Phase II study of pembrolizumab or pembrolizumab plus bevacizumab for recurrent glioblastoma (rGBM) patients. J Clin Oncol 2018;36:2006.

81 He Y, Rivard CJ, Rozeboom L, et al. Lymphocyte-Activation gene-3, an important immune checkpoint in cancer. Cancer Sci 2016;107:1193-7.

82 Liu Z, Meng Q, Bartek J, et al. Tumor-Infiltrating lymphocytes (TILs) from patients with glioma. Oncoimmunology 2017;6:e1252894.

83 Dougall WC, Kurtulus S, Smyth MJ, et al. TIGIT and CD96: new checkpoint receptor targets for cancer immunotherapy. Immunol Rev 2017;276:112-20.

84 Vasquez JC, Huttner A, Zhang L, et al. SOX2 immunity and tissue resident memory in children and young adults with glioma. $J$ Neurooncol 2017:134:41-53.

85 Hung AL, Maxwell R, Theodros D, et al. TIGIT and PD-1 dual checkpoint blockade enhances antitumor immunity and survival in GBM. Oncoimmunology 2018;8:e1466769.

86 Cheng L, Ruan Z. Tim-3 and Tim- 4 as the potential targets for antitumor therapy. Hum Vaccin Immunother 2015;11:2458-62.

87 Li G, Wang Z, Zhang C, et al. Molecular and clinical characterization of Tim-3 in glioma through 1,024 samples. Oncoimmunology 2017;6:e1328339. 
88 Liu Z, Han H, He X, et al. Expression of the galectin-9-Tim-3 pathway in glioma tissues is associated with the clinical manifestations of glioma. Oncol Lett 2016;11:1829-34.

89 Han S, Feng S, Xu L, et al. Tim-3 on peripheral CD4 ${ }^{+}$and CD8 T cells is involved in the development of glioma. DNA Cell Biol 2014;33:245-50.

90 Goods BA, Hernandez AL, Lowther DE, et al. Functional differences between PD-1+ and PD-1- CD4+ effector T cells in healthy donors and patients with glioblastoma multiforme. PLoS One 2017;12:e0181538.

91 Li J, Liu X, Duan Y, et al. Combined blockade of T cell immunoglobulin and mucin domain 3 and carcinoembryonic antigen-related cell adhesion molecule 1 results in durable therapeutic efficacy in mice with intracranial gliomas. Med Sci Monit 2017;23:3593-602.

92 Kim JE, Patel MA, Mangraviti A, et al. Combination therapy with anti-PD-1, Anti-TIM-3, and focal radiation results in regression of murine gliomas. Clin Cancer Res 2017;23:124-36.

93 Leone RD, Lo Y-C, Powell JD. A2aR antagonists: next generation checkpoint blockade for cancer immunotherapy. Comput Struct Biotechnol J 2015;13:265-72.

94 Xu S, Shao Q-Q, Sun J-T, et al. Synergy between the ectoenzymes CD39 and CD73 contributes to adenosinergic immunosuppression in human malignant gliomas. Neuro Oncol 2013;15:1160-72.

95 Li G, Quan Y, Che F, et al. B7-H3 in tumors: friend or foe for tumor immunity? Cancer Chemother Pharmacol 2018;81:245-53.

96 Chapoval Al, Ni J, Lau JS, et al. B7-H3: a costimulatory molecule for T cell activation and IFN-gamma production. Nat Immunol 2001;2:269-74.

97 Suh W-K, Gajewska BU, Okada H, et al. The B7 family member B7$\mathrm{H} 3$ preferentially down-regulates $\mathrm{T}$ helper type 1-mediated immune responses. Nat Immunol 2003;4:899-906.

98 Prasad DVR, Nguyen T, Li Z, et al. Murine B7-H3 is a negative regulator of T cells. J Immunol 2004;173:2500-6.

99 Wang Z, Wang Z, Zhang C, et al. Genetic and clinical characterization of B7-H3 (CD276) expression and epigenetic regulation in diffuse brain glioma. Cancer Sci 2018;109:2697-705

100 Baral A, Ye HX, Jiang PC, et al. B7-H3 and B7-H1 expression in cerebral spinal fluid and tumor tissue correlates with the malignancy grade of glioma patients. Oncol Lett 2014;8:1195-201.

101 Lemke D, Pfenning P-N, Sahm F, et al. Costimulatory protein $4 \mathrm{lgB} 7 \mathrm{H} 3$ drives the malignant phenotype of glioblastoma by mediating immune escape and invasiveness. Clin Cancer Res 2012:18:105-17.

102 Flies DB, Wang S, Xu H, et al. Cutting edge: a monoclonal antibody specific for the programmed death- 1 homolog prevents graft-versus-host disease in mouse models. $J$ Immunol 2011;187:1537-41.

103 Le Mercier I, Chen W, Lines JL, et al. Vista regulates the development of protective antitumor immunity. Cancer Res 2014;74:1933-44.

104 Flies DB, Han X, Higuchi T, et al. Coinhibitory receptor PD-1H preferentially suppresses $\mathrm{CD} 4^{+} \mathrm{T}$ cell-mediated immunity. J Clin Invest 2014:124:1966-75.

105 Prasad DVR, Richards S, Mai XM, et al. B7S1, a novel B7 family member that negatively regulates $\mathrm{T}$ cell activation. Immunity 2003;18:863-73.

106 Sica GL, Choi IH, Zhu G, et al. B7-H4, a molecule of the B7 family, negatively regulates T cell immunity. Immunity 2003;18:849-61.

107 Mo L-J, Ye H-X, Mao Y, et al. B7-H4 expression is elevated in human U251 glioma stem-like cells and is inducible in monocytes cultured with U251 stem-like cell conditioned medium. Chin J Cancer 2013;32:653-60

108 Yao Y, Ye H, Qi Z, et al. B7-H4(B7x)-Mediated Cross-talk between Glioma-Initiating Cells and Macrophages via the IL6/JAK/STAT3 Pathway Lead to Poor Prognosis in Glioma Patients. Clin Cancer Res 2016;22:2778-90.

109 Zarganes-Tzitzikas T, Konstantinidou M, Gao Y, et al. Inhibitors of programmed cell death 1 (PD-1): a patent review (2010-2015). Expert Opin Ther Pat 2016;26:973-7.

110 Chupak LS DM, Martin SW, Zheng X, et al. Compounds useful as immunomodulators 2015.

111 Skalniak L, Zak KM, Guzik K, et al. Small-Molecule inhibitors of PD-1/PD-L1 immune checkpoint alleviate the PD-L1-induced exhaustion of T-cells. Oncotarget 2017;8:72167-81.

112 Van Audenhove I, Gettemans J. Nanobodies as versatile tools to understand, diagnose, visualize and treat cancer. EBioMedicine 2016;8:40-8.

113 Cortez-Retamozo V, Lauwereys M, Hassanzadeh Gh G, et al. Efficient tumor targeting by single-domain antibody fragments of camels. Int J Cancer 2002:98:456-62.
114 Dumoulin M, Conrath K, Van Meirhaeghe A, et al. Single-Domain antibody fragments with high conformational stability. Protein $\mathrm{Sci}$ 2002;11:500-15.

115 Vincke C, Loris R, Saerens D, et al. General strategy to humanize a camelid single-domain antibody and identification of a universa humanized nanobody scaffold. J Biol Chem 2009;284:3273-84.

116 Lamichhane P, Deshmukh R, Brown JA, et al. Novel delivery systems for checkpoint inhibitors. Medicines 2019;6:74.

117 Duggan S. Caplacizumab: first global approval. Drugs 2018;78:1639-42

118 Zhang F, Wei H, Wang X, et al. Structural basis of a novel PDL1 nanobody for immune checkpoint blockade. Cell Discov 2017;3:17004

119 Sun X, Yan X, Zhuo W, et al. Pd-L1 nanobody competitively inhibits the formation of the PD-1/PD-L1 complex: comparative molecular dynamics simulations. Int J Mol Sci 2018;19:1984.

120 Neelapu SS, Locke FL, Bartlett NL, et al. Axicabtagene Ciloleucel CAR T-cell therapy in refractory large B-cell lymphoma. $N$ Engl J Med 2017:377:2531-44.

121 Schuster SJ, Bishop MR, Tam CS, et al. Tisagenlecleucel in adult relapsed or refractory diffuse large B-cell lymphoma. N Engl J Med 2019;380:45-56.

122 Xie YJ, Dougan M, Jailkhani N, et al. Nanobody-based CAR T cells that target the tumor microenvironment inhibit the growth of solid tumors in immunocompetent mice. Proc Natl Acad Sci U S A 2019;116:7624-31.

123 Liu X, Ranganathan R, Jiang S, et al. A chimeric Switch-Receptor targeting PD1 augments the efficacy of second-generation CAR T cells in advanced solid tumors. Cancer Res 2016;76:1578-90.

124 Suarez ER, Chang DK, Sun J, et al. Chimeric antigen receptor T cells secreting anti-PD-L1 antibodies more effectively REGRESS renal cell carcinoma in a humanized mouse model. Oncotarget 2016;7:34341-55.

125 Oh T, Sayegh ET, Fakurnejad S, et al. Vaccine therapies in malignant glioma. Curr Neurol Neurosci Rep 2015;15:508.

126 Phuphanich S, Wheeler CJ, Rudnick JD, et al. Phase I trial of a multi-epitope-pulsed dendritic cell vaccine for patients with newly diagnosed glioblastoma. Cancer Immunol Immunother 2013:62:125-35.

127 Humphrey PA, Wong AJ, Vogelstein B, et al. Anti-synthetic peptide antibody reacting at the fusion junction of deletion-mutant epidermal growth factor receptors in human glioblastoma. Proc Natl Acad Sci U S A 1990;87:4207-11.

128 Heimberger AB, Suki D, Yang D, et al. The natural history of EGFR and EGFRvIll in glioblastoma patients. J Trans/ Med 2005;3:38.

129 Sampson JH, Heimberger AB, Archer GE, et al. Immunologic escape after prolonged progression-free survival with epidermal growth factor receptor variant III peptide vaccination in patients with newly diagnosed glioblastoma. J Clin Oncol 2010;28:4722-9.

130 Reardon DA, Schuster J, Tran DD, et al. React: overall survival from a randomized phase II study of rindopepimut (CDX-110) plus bevacizumab in relapsed glioblastoma. J Clin Oncol 2015;33:2009.

131 Weller M, Butowski N, Tran DD, et al. Rindopepimut with temozolomide for patients with newly diagnosed, EGFRvIllexpressing glioblastoma (act IV): a randomised, double-blind, International phase 3 trial. Lancet Oncol 2017;18:1373-85.

132 Chandramohan V, Bryant JD, Piao H, et al. Validation of an immunohistochemistry assay for detection of CD155, the poliovirus receptor, in malignant gliomas. Arch Pathol Lab Med 2017;141:1697-704.

133 Desjardins A, Gromeier M, Herndon JE, et al. Recurrent glioblastoma treated with recombinant poliovirus. $N$ Engl J Med 2018;379:150-61.

134 Beckmann RP, Mizzen LE, Welch WJ. Interaction of HSP 70 with newly synthesized proteins: implications for protein folding and assembly. Science 1990;248:850-4.

135 Basu S, Binder RJ, Suto R, et al. Necrotic but not apoptotic cell death releases heat shock proteins, which deliver a partial maturation signal to dendritic cells and activate the NF-kappa B pathway. Int Immunol 2000;12:1539-46.

136 Gurbuxani S, Bruey JM, Fromentin A, et al. Selective depletion of inducible Hsp70 enhances immunogenicity of rat colon cancer cells. Oncogene 2001;20:7478-85.

137 Suto R, Srivastava PK. A mechanism for the specific immunogenicity of heat shock protein-chaperoned peptides. Science 1995;269:1585-8.

138 Pawaria S, Binder RJ. CD91-dependent programming of T-helper cell responses following heat shock protein immunization. Nat Commun 2011:2:521. 
139 Delneste Y, Magistrelli G, Gauchat J, et al. Involvement of LOX-1 in dendritic cell-mediated antigen cross-presentation. Immunity 2002;17:353-62.

140 Ohashi K, Burkart V, Flohé S, et al. Cutting edge: heat shock protein 60 is a putative endogenous ligand of the Toll-like receptor-4 complex. J Immunol 2000;164:558-61.

141 Bloch O, Crane CA, Fuks Y, et al. Heat-Shock protein peptide complex-96 vaccination for recurrent glioblastoma: a phase II, single-arm trial. Neuro Oncol 2014;16:274-9.

142 Lipscomb MF, Masten BJ. Dendritic cells: immune regulators in health and disease. Physiol Rev 2002;82:97-130.

143 Sampson JH, Archer GE, Mitchell DA, et al. An epidermal growth factor receptor variant III-targeted vaccine is safe and immunogenic in patients with glioblastoma multiforme. Mol Cancer Ther 2009;8:2773-9.

144 Akiyama Y, Oshita C, Kume A, et al. $\alpha$-type-1 polarized dendritic cell-based vaccination in recurrent high-grade glioma: a phase clinical trial. BMC Cancer 2012;12:623.

145 Prins RM, Wang X, Soto H, et al. Comparison of glioma-associated antigen peptide-loaded versus autologous tumor lysate-loaded dendritic cell vaccination in malignant glioma patients. $J$ Immunother 2013;36:152-7.
146 Gorsi HS, Malicki DM, Barsan V, et al. Nivolumab in the treatment of recurrent or refractory pediatric brain tumors: a single institutional experience. J Pediatr Hematol Oncol 2019;41:e235-41.

147 Dunn IF, Du Z, Touat M, et al. Mismatch repair deficiency in high-grade meningioma: a rare but recurrent event associated with dramatic immune activation and clinical response to PD-1 blockade. JCO Precis Oncol 2018;2018. doi:10.1200/PO.18.00190. [Epub ahead of print: 27 Nov 2018].

148 Gelerstein E, Berger A, Jonas-Kimchi T, et al. Regression of intracranial meningioma following treatment with nivolumab: case report and review of the literature. J Clin Neurosci 2017;37:51-3.

149 Nayak L, Iwamoto FM, LaCasce A, et al. PD-1 blockade with nivolumab in relapsed/refractory primary central nervous system and testicular lymphoma. Blood 2017;129:3071-3.

150 Riccardi C, Cifone MG, Migliorati G. Glucocorticoid hormoneinduced modulation of gene expression and regulation of T-cell death: role of GITR and GILZ, two dexamethasone-induced genes. Cell Death Differ 1999;6:1182-9.

151 Liu J, Blake SJ, Yong MCR, et al. Improved efficacy of neoadjuvant compared to adjuvant immunotherapy to eradicate metastatic disease. Cancer Discov 2016;6:1382-99. 


\section{Correction: T lymphocyte-targeted immune checkpoint modulation in glioma}

Kelly WJ, Giles AJ, Gilbert M. T lymphocyte-targeted immune checkpoint modulation in glioma. J Immunotherapy Cancer 2020;8:e000379. doi: 10.1136/jitc-2019-000379

Since the online publication of this article, the corresponding author has provided a new email address; William Kelly william.kelly@nih.gov.

Open access This is an open access article distributed in accordance with the Creative Commons Attribution Non Commercial (CC BY-NC 4.0) license, which permits others to distribute, remix, adapt, build upon this work non-commercially, and license their derivative works on different terms, provided the original work is properly cited, appropriate credit is given, any changes made indicated, and the use is non-commercial. See http://creativecommons.org/licenses/by-nc/4.0/.

(C) Author(s) (or their employer(s)) 2020. Re-use permitted under CC BY-NC. No commercial re-use. See rights and permissions. Published by BMJ.

J Immunother Cancer 2020;8:e000379corr1. doi:10.1136/jitc-2019-000379corr1 